\title{
Vibration Test Measures for Pump Fault Diagnosis
}

\author{
Lian Shi*, Lei Liu \\ Zibo Product Quality Testing Research Institute, Zibo 25500, Shangdong Province, China
}

*Corresponding author: Lian Shi, $511259551 @ q q . c o m$

\begin{abstract}
The vibration measuring standard for compound machinery utilized in modern industrial production will be employed for the application of detecting technologies. The vibration intensity can be obtained by selecting the detecting method to obtain the speed of mechanical vibration, and technicians can examine whether the vibrating machinery is in a proper functioning state based on the value of vibration intensity, allowing for thorough fault diagnosis. In order to provide useful diagnosis ideas for technicians, this study examines the measurement of mechanical vibration and investigates the calculating method of mechanical vibration intensity.
\end{abstract}

Keywords: Vibration test; Pump; Calculation; Diagnosis

Publication date: November 2021; Online publication: November 30, 2021

\section{Introduction}

Pumps used in industrial production are mainly used to transport raw materials, including liquid materials such as water, oil and emulsion, or to transport some suspended solids. At present, most of the pump machinery used in domestic industrial production are imported equipment, and the fault monitoring and fault diagnosis of pumps need to be completed by domestic technicians. Therefore, technicians should better understand the fault detection mode of the pump, clarify the vibration test standard of the pump, and make accurate judgment on the fault of pump equipment. Taking the test of bearing and pressure end of F-1300 ordinary drilling pump as an example, it can illustrate the fault diagnosis of pump equipment.

\section{Pump mechanical vibration test}

\subsection{Speed test principle}

According to the analysis of physical properties during the measurement of pump equipment, the test methods of vibration speed can be mainly divided into three kinds, including mechanical measurement method, electrical measurement method and optical measurement method. In this test, the vibration speed is controlled by means of acceleration sensor, the acceleration signal is A / D converted, filtered into DC signal, and then filtered to meet certain requirements. Technicians can use digital frequency domain filtering. The advantage of this approach is that it is relatively simple, and the calculation speed is relatively fast, the control accuracy of the filtering frequency band is relatively high, it has strong flexibility, and does not produce time shift effects, The actual generated data has gone through the process of MATLAB numerical processing. The process is to pass the acceleration signal a, obtain high-pass filtering, and send out the speed signal. After the trend term is removed by the polynomial fitting data, the usable speed signal is obtained. This is the speed test principal process ${ }^{[1]}$.

\subsection{Arrange the pump vibration speed tester}

As shown in Figure 1 and Figure 2, it is the layout mode of pump bearing and hydraulic end vibration test of F-1300 ordinary drilling equipment in the test. 


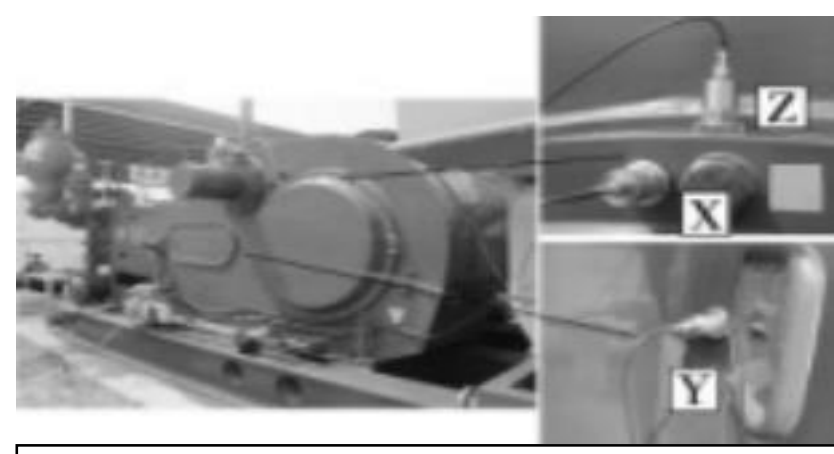

Figure 1. Schematic diagram of test instrument at pump bearing (Reference)

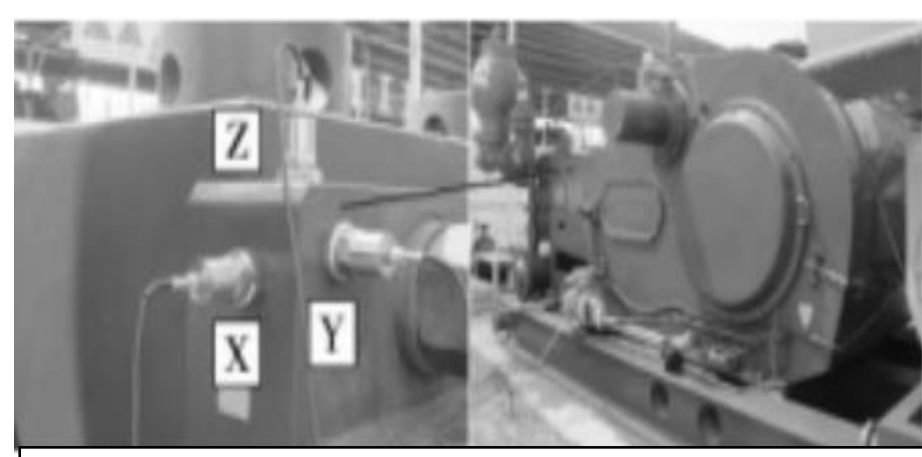

Figure 2. Schematic diagram of test instrument at hydraulic end of pump (Reference)

\subsection{Collect vibration signal}

From obtaining the measured signal, it is sent to the piezoelectric acceleration sensor, then input to the KD5018 charge amplifier, recorded to the NI9205 data acquisition card, and the discrete digital signal is given through the notebook ${ }^{[2]}$.

\subsection{Process vibration signal}

Technicians can use MATLAB to collect data. Different processing speeds can be obtained with the change of time. For example, the change of $\mathrm{X}$ and $\mathrm{Y}$ points shown in Figure 3 and Figure $\mathbf{4}$ can obtain the integral speed graph.

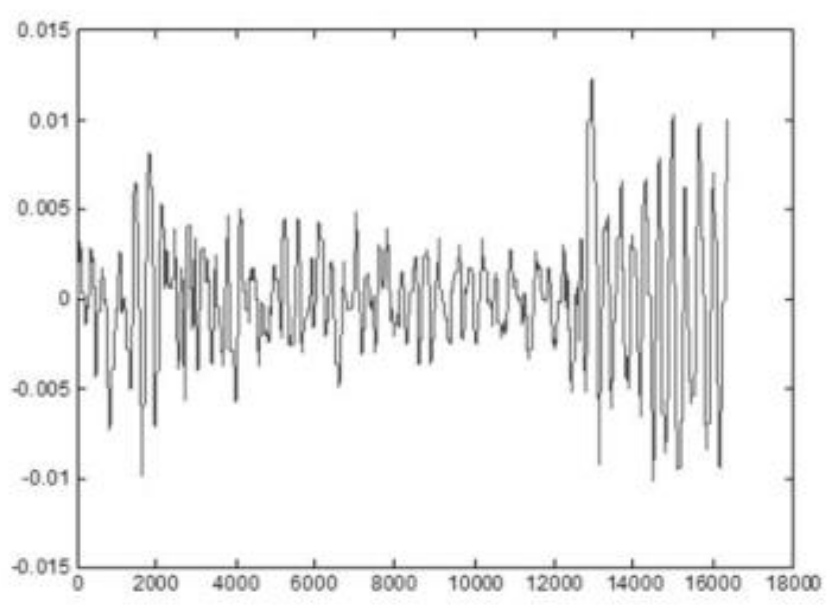

Figure 3. Calculation results of frequency domain integration of $\mathrm{X}$-direction detrended term (Reference)

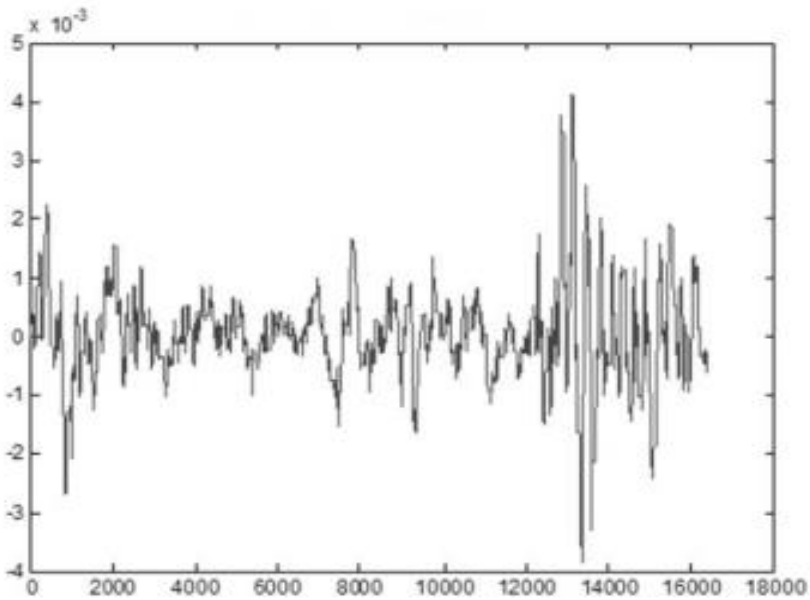

Figure 4. Calculation results of frequency domain integration of $\mathrm{Y}$-direction detrended term (Reference)

\section{Pump mechanical vibration intensity calculation}

The vibration intensity of pump machinery can be defined as the frequency range, which is the root mean square value of vibration speed of $10-1000 \mathrm{~Hz}$. For example, the vibration signal is $\mathrm{v}(\mathrm{t})$, the calculation time is $\mathrm{T}$, the vibration intensity is $(1) \mathrm{v}=\sqrt{ } \frac{1}{\mathrm{~T}} \int_{\mathrm{o}}^{\mathrm{T}} \mathrm{v} 2(t) \mathrm{dt}$, the square root value can be taken within the range of signal $v(t)$ in $(0, t)$, the discrete vibration velocity signal at point $n$ is $v(n)$, and the calculation formula can also be written as (2) $V=\sqrt{ } \frac{1}{N} \sum_{n}^{N-1} v 2(n)$. For the standard of strong vibration, refer to the contents in the 
"Method for Measuring and rating vibration of Reciprocating Machines" issued by relevant national departments, that is, the contents shown in Table 1.

Table 1. "Reciprocating Machinery Vibration Measurement and Rating Methods" issued by relevant national departments (Reference)

\begin{tabular}{|c|c|c|c|c|c|}
\hline \multicolumn{2}{|c|}{ Vibration intensity } & \multicolumn{4}{c|}{ Vibration quality } \\
\hline Range & Effective value of speed / mm / S & Class I & Class II & Class III & Class IV \\
\hline 0.071 & - & & & & \\
\hline 0.11 & 0.11 & Excellent & & & \\
\hline 0.18 & 0.18 & & Excellent & & \\
\hline 0.28 & 0.28 & & & Excellent & \\
\hline 0.45 & 0.45 & & & & Excellent \\
\hline 0.71 & 0.71 & Good & & & \\
\hline 1.12 & 1.12 & & Good & & \\
\hline 1.8 & 1.8 & Allowed & & Good & \\
\hline 2.8 & 2.8 & & Allowed & & Good \\
\hline 4.5 & 4.5 & Not allowed & & Allowed & \\
\hline 7.1 & 7.1 & & Not allowed & & Allowed \\
\hline 11.2 & 11.2 & & & Not allowed & \\
\hline 18 & 18 & & & & Not allowed \\
\hline 28 & 28 & & & & \\
\hline 45 & 45 & & & & \\
\hline 71 & 71 & & & & \\
\hline
\end{tabular}

The vibration intensity can be calculated according to the principle of 36 by referring to (1) and (2) in the MATLAB formula. The integral calculation method of detrended term is adopted to calculate the direction intensity of $\mathrm{X}$ and $\mathrm{Y}$, and the corresponding mean value and standard deviation are given. In the bearing, the calculation results can be reflected in Table 2 and Table 3. And the calculation results of the hydraulic end of pump mechanical equipment can be reflected in Table $\mathbf{4}$ and Table 5. The values are all derived from the vibration intensity in this direction, the vibration intensity in the X direction is $3.1928 \mathrm{~mm} / \mathrm{s}$, the vibration intensity in the $\mathrm{Y}$ direction is $0.8202 \mathrm{~mm} / \mathrm{s}$, and the vibration intensity in the $\mathrm{X}$ direction is the largest. Petroleum mechanical equipment belongs to class IV, and the evaluation of technical conditions is good. The value is the vibration intensity in this direction, the vibration intensity in the $\mathrm{X}$ direction is $0.9652 \mathrm{~mm} / \mathrm{s}$, the vibration intensity in the $Y$ direction is $1.2771 \mathrm{~mm} / \mathrm{s}$, and the vibration intensity in the $Y$ direction is the largest. This kind of machinery is classified as class IV. Therefore, the evaluation of its technical condition is excellent ${ }^{[3]}$.

\section{Common faults of drilling pump and location of test points}

During the operation of the drilling pump, irregular vibration problems often occur. Some vibration signals are generated by the operation of the machine, and some vibration may also be caused by abnormal parts in the pump. If the drilling pump fails and the mechanical equipment cannot operate normally, the vibration signals generated at different positions will have different reactions in the equipment. Therefore, technicians should find accurate test points in vibration test and judge which form vibration belongs to. For example, judge whether the drilling pump belongs to the vibration generated under normal working 
conditions, judge whether the drilling pump cycle has regular vibration, judge whether the vibration is caused by defects in design and processing, whether the vibration belongs to irregular fault problems, and whether it is caused by mechanical resonance around the mine. In practice, it can be seen that the vibration of most pump equipment is related to the regular vibration caused by the periodic cycle, which may be because the vibration signals caused by the surrounding machines are considered to be the same signals based on the filtering of clutter signals. If it is the fault diagnosis of pump equipment, it is not a regular signal, so it is easy to identify, technical personnel can also locate it accurately, which is more beneficial to the overall mechanical fault judgment ${ }^{[4]}$.

The hydraulic end of the drilling pump includes components such as discharge valve and suction valve. If these parts are damaged, they will affect the vibration of the faulty equipment. For example, the piston in the pump equipment is mainly in the form of periodic movement, and the friction generated in the movement will form impact wear. In the process of downward reciprocating movement, the parts may fail. Among them, the piston rod and the intermediate rod are connected by clamps, so technicians need to monitor it in real time. There may be vibration impact between the valve body and the valve seat due to operation, but the main causes of these problems are caused by the failure of the pump valve. Therefore, the abnormal vibration of pump equipment components will be transmitted to the valve box. If the power end of the drilling pump equipment is faulty, it may be because the crosshead of the reciprocating pump is subjected to a huge impact force during operation, and the lubrication effect of the bearing part is not ideal, so the wear problem will be exacerbated, and the vibration frequency will be expanded, resulting in greater friction between gears, and then the gear may fail in operation, and the abnormal vibration of these components will be very obvious in the body. The technicians selected the appropriate sampling frequency according to the sampling theorem. Referring to the normal working condition of the drilling pump, the normal vibration frequency is within $5000 \mathrm{~Hz}$. Therefore, if the sampling frequency is greater than this value, it can indicate that the vibration is abnormal.

Table 2. Vibration intensity at pump bearings (Reference)

\begin{tabular}{|c|c|c|c|c|c|c|c|c|c|c|c|c|c|c|c|}
\hline $\begin{array}{l}\text { Numbe } \\
\text { r of } \\
\text { data } \\
\text { groups }\end{array}$ & \multicolumn{3}{|c|}{1} & \multicolumn{3}{|c|}{2} & \multicolumn{3}{|c|}{3} & \multicolumn{3}{|c|}{4} & \multicolumn{3}{|c|}{5} \\
\hline $\begin{array}{l}\text { Measur } \\
\text { ement } \\
\text { directio } \\
\text { n }\end{array}$ & $X$ & $\mathrm{Y}$ & $\mathrm{Z}$ & $X$ & $\mathrm{Y}$ & $\mathrm{Z}$ & $X$ & $Y$ & $\mathrm{Z}$ & $X$ & $\mathrm{Y}$ & $\mathrm{Z}$ & $X$ & $\mathrm{Y}$ & $\mathrm{Z}$ \\
\hline $\begin{array}{l}\text { Vibrati } \\
\text { on } \\
\text { intensit } \\
y\end{array}$ & $\begin{array}{l}3.3 \\
803\end{array}$ & $\begin{array}{c}0.7 \\
728\end{array}$ & $\begin{array}{l}1.2 \\
658\end{array}$ & $\begin{array}{l}3.1 \\
655\end{array}$ & $\begin{array}{c}0.77 \\
776\end{array}$ & $\begin{array}{l}1.1 \\
821\end{array}$ & $\begin{array}{l}2.9 \\
811\end{array}$ & $\begin{array}{l}0.8 \\
685\end{array}$ & $\begin{array}{c}1.4 \\
936\end{array}$ & $\begin{array}{l}3.4 \\
786\end{array}$ & $\begin{array}{c}0.7 \\
917\end{array}$ & $\begin{array}{l}1.2 \\
792\end{array}$ & $\begin{array}{l}2.9 \\
583\end{array}$ & $\begin{array}{c}0.8 \\
904\end{array}$ & $\begin{array}{c}1.3 \\
224\end{array}$ \\
\hline
\end{tabular}

Table 3. Mean and standard deviation of vibration intensity at pump bearings (Reference)

\begin{tabular}{|c|c|c|c|c|c|}
\hline \multicolumn{2}{|c|}{ X } & \multicolumn{2}{c|}{ Y } & \multicolumn{2}{c|}{ Z } \\
\hline Mean value & Standard deviation & Mean value & Standard deviation & Mean value & Standard deviation \\
\hline 3.1928 & 0.0543 & 0.8202 & 0.0030 & 1.3086 & 0.0133 \\
\hline
\end{tabular}


Table 4. Vibration intensity of hydraulic end of pump (Reference)

\begin{tabular}{|c|c|c|c|c|c|c|c|c|c|c|c|c|c|c|c|}
\hline $\begin{array}{l}\text { Number } \\
\text { of data } \\
\text { groups }\end{array}$ & \multicolumn{3}{|c|}{1} & \multicolumn{3}{|c|}{2} & \multicolumn{3}{|c|}{3} & \multicolumn{3}{|c|}{4} & \multicolumn{3}{|c|}{5} \\
\hline $\begin{array}{l}\text { Measure } \\
\text { ment } \\
\text { direction }\end{array}$ & $X$ & $\mathrm{Y}$ & $\mathrm{Z}$ & $X$ & $\mathrm{Y}$ & $\mathrm{Z}$ & $X$ & $\mathrm{Y}$ & $\mathrm{Z}$ & $X$ & $\mathrm{Y}$ & $\mathrm{Z}$ & $X$ & $\mathrm{Y}$ & $\mathrm{Z}$ \\
\hline $\begin{array}{l}\text { Vibration } \\
\text { intensity }\end{array}$ & $\begin{array}{l}0 . \\
87 \\
86\end{array}$ & $\begin{array}{l}1.3 \\
181\end{array}$ & $\begin{array}{c}1.1 \\
578\end{array}$ & $\begin{array}{l}1.0 \\
033\end{array}$ & $\begin{array}{l}1.2 \\
323\end{array}$ & $\begin{array}{c}1.2 \\
420\end{array}$ & $\begin{array}{l}1.1 \\
554\end{array}$ & $\begin{array}{l}1.2 \\
298\end{array}$ & $\begin{array}{l}1.1 \\
251\end{array}$ & $\begin{array}{l}0.8 \\
673\end{array}$ & $\begin{array}{l}1.3 \\
432\end{array}$ & $\begin{array}{l}1.2 \\
636\end{array}$ & $\begin{array}{l}0.9 \\
213\end{array}$ & $\begin{array}{l}1.2 \\
621\end{array}$ & $\begin{array}{c}0.9 \\
990\end{array}$ \\
\hline
\end{tabular}

Table 5. Mean and standard deviation of vibration intensity of hydraulic end of pump (Reference)

\begin{tabular}{|c|c|c|c|c|c|}
\hline \multicolumn{2}{|c|}{ X } & \multicolumn{2}{c|}{ Y } & \multicolumn{2}{c|}{ Z } \\
\hline Mean value & Standard deviation & Mean value & Standard deviation & Mean value & Standard deviation \\
\hline 0.9652 & 0.0142 & 1.2771 & 0.0026 & 1.1575 & 0.0111 \\
\hline
\end{tabular}

\section{Conclusion}

In industrial production, pump equipment collects signals through vibration, and the vibration intensity can be obtained by processing data with MATLAB. Then, the working condition of pump equipment can be evaluated according to relevant standards, including four grades: excellent, good, general and poor. Technicians can give evaluation opinions according to the results. If the evaluation result is not good, it can be stopped for rectification. If the evaluation result is good, production can be arranged normally. In the process of calculating vibration intensity from spectrum method, technicians can relax the requirements for vibration signal, provide convenience for calculating frequency, help to enhance the flexibility and applicability of calculation, reduce the influence of signal randomness and make the calculation result more stable.

\section{Disclosure statement}

The author declares no conflict of interest.

\section{References}

[1] Zhang JY, Pan ZC, Zhou HB, et al., 2020, Fault Diagnosis of Vacuum On-Load Tap Changer Based on Vibration Test. Transformer, 57(11): 56-59.

[2] Zhang JC, Wang LC, 2019, Application of Vibration Testing Analysis Technique in Equipment Fault Diagnosis. China New Telecommunications, 21(09): 123.

[3] Yu L, Yang YM, Zhong GX, et al., 2018, Testing Point Optimization of Drilling Pump Fault Diagnosis Based on Vibration Testing. Development \& Innovation of Machinery \& Electrical Products, 31(02): 66-69.

[4] Liu WF, 2017, Application of Vibration Measurement Technology in Fault Diagnosis of Rotating Equipment. Coal Science and Technology, 45(1): 161-163. 